\title{
NEW EXPERIMENT SYSTEM FOR THE INTERACTION BETWEEN SOFT ROCK AND WATER: A CASE STUDY ON THE MOGAO GROTTOES SUPPORT ROCK
}

\author{
Zhu Guolong*, Qin Xinzhan, Hao Nai and Zhang Fang \\ China University of Mining and Technology, Beijing, P. R. China
}

\begin{abstract}
The strength of rock strongly depends on the water content especially when the rocks contain clay materials. The interaction between soft rock and water always threaten the soft rock engineering projects. For this problem, new sets of laboratory experiment systems are developed to simulate the interaction between soft rock and water or vapor. In this paper, the principles of experiment systems are introduced with particular reference to the application on soft rock in Mogao Grottoes, one of the world famous ancient sites in China. Two kinds of rock samples, the sandstone and muddy sandstone, are obtained by insitu sampling system. Then the laboratory experiments are performed under different environment conditions. By the specific boundary conditions design, the physical-chemical effect and mechanic effect on water absorption of rock samples are separated for further mechanism study by the experiment system, and the different hydrological actions of water and vapor under variable experiment environment are obtained. The interaction mechanism is discussed with assistant methods, such as SEM (Scanning Electron Microscope), mercury injection test, X-ray diffraction analysis and etc. With the relation between water content and soft rock strength, the study may provide guidance and basis for the soft rock engineering in the future.
\end{abstract}

\section{INTRODUCTION}

Soft Rocks always present undesirable behaviors, such as low strength, disaggregation, crumbling, high plasticity, slaking, fast weathering and many other characteristics.[1] Previous study shows that the strength of rock strongly depends on the water content especially when the rocks contain clay materials. The interaction between soft rock and water always threaten the soft rock engineering projects. Taking the Mogao Caves site in Dunhuang, China, as an example, this culture relics is one of the largest stone caves temples in China. It is located in the Duanming Moutain and the extensive studies on common issues and challenges in classification, mechanism, assessment, protection and repair of Mogao Caves have been carried out. But the soft surrounding rocks and the paintings support rocks are suffering serious. Researches on soft rock culture relics protection and preservation, represented by the Mogao Caves , play significant roles in retaining the precious of remarkable ancient China, therefore it is of a great significance to achieve effective protection and long-term preservation to cultural relics [2].

At present, there are less focus on the risks associated to the rock failure. Some researchers put efforts on earthquake risk analysis to the Dunhuang site which can cause damages to the support rock of the caves and unrepairable disasters to cultural relics can happen [3,4]. Other sources like physical damage, salinization, and weathering of support can also bring disastrous damage $[5,6]$. In-situ tests fit conditions of rare cultural relics, but they should be performed in order to avoid DOI: $10.5121 / \mathrm{msej} .2016 .3303$ 
risks to the relics, however non destructive tests are always a better option. Therefore, laboratory tests should be employed. The main factors, such as temperature, humidity, freezing, melting weathering and salination damage, were studied by predecessors, and the influence of water is a common key issue for the cultural relics' protection. Difficulties lays in in-situ sampling, laboratory testing method, and corresponding experiment systems development are still obvious, forming an urgent need for new ideas, technology and experimental equipments developments.

GDUE (State Key Laboratory for Geomechanics and Deep Underground Engineering from China University of Mining and Technology, Beijing) performs long-term researches on soft rock, clay minerals, failure mechanism, geotechnical laboratory testing, and real-time remote monitoring and control techniques, with remarkable achievements. In this study, combined with the experience of GDUE, researches on Mogao caves rock weathering at different levels were proposed under coupled multi-field environment. A self-developed sampling system was used for field sampling, and then the samples were used in new laboratory equipments [7-11].

In this paper, new sets of laboratory experiment systems are developed to simulate the interaction between soft rock and water or vapor. The principles of experiment systems are introduced with particular reference to the application on soft rock weathering in Mogao Grottoes, and the in-situ environment conditions, the atmospheric humidity influenced by the weather and the local environment in the caves influenced by outside were considered. A new laboratory experiment system was developed to simulate the coupled temperature and humidity environment for the surrounding rock and support of wall paintings. The main technical parameters of the system was tested, proving that it can realize long time constant temperature and humidity control, and can be applied to the weathering mechanism study on Mogao Caves stones. It indicates that the microstructure and the basic mechanical properties of the situ samples have changed at different environment conditions. For further research, SEM (Scanning Electron Microscope), mercury injection test, X-ray diffraction analysis were also performed. Sample composition, microstructure and properties were studied from the microscopic view. From the mesoscopic view, the physical parameters and mechanical properties of samples were studied. Finally analysis are performed on macro-failure mechanism based on above, expecting to provide new theoretical support for the protection and preservation of cultural relics sites.

\section{EXPERIMENT SYSTEMS}

The soft rock absorption mechanism is complicated for the combination of physical absorption by capillary and structure effects, the mechanical absorption by the water head or pressure and the chemical effect by clay minerals and other materials. For this problem, the first water absorption system in GDUE was improved and upgraded in 2015, and the water vapor absorption system was designed and developed. The different mechanism of water absorption can be studied seperately.

\subsection{Water absorption system}

Two kinds of water absorption (WA) experiment are designed as the following diagrams. Figure 1a shows the WA experiment without water head pressure, the connection between the soft pipe and measuring glass were set at the same level to separate mechanical effect. Then, the experiment in Figure $1 \mathrm{~b}$ considered the physical, chemical and mechanical effects. The WA value was acquired by the monitoring system automatically and draw the curve in the computer. With 
the combinition of the above two experiments, the mechanical effect in the soft rock water absorption was evaluated.

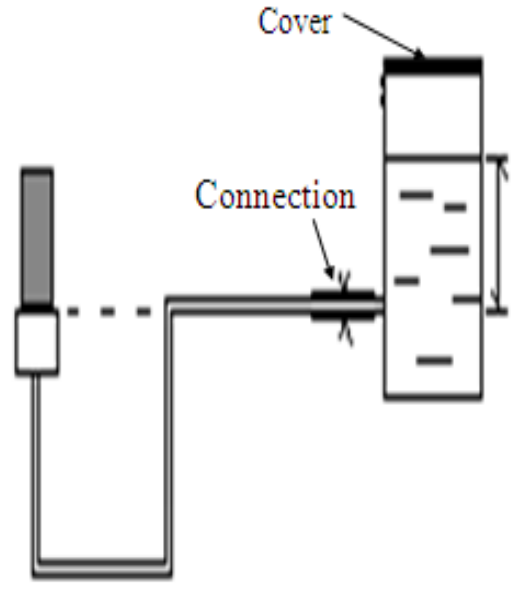

(a)

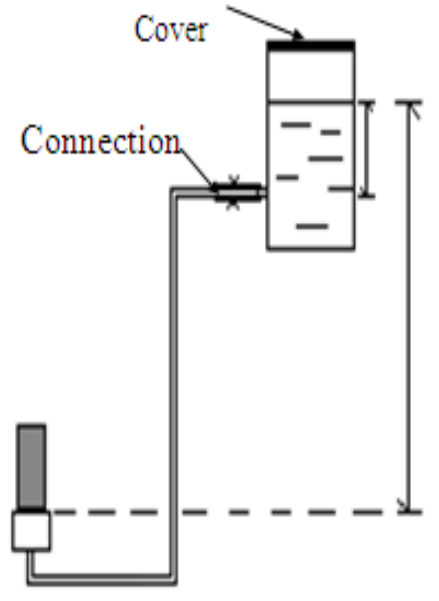

(b)

Fig.1 Mechanism of Soft Rock Water Absorption Experiment System: a, experiment without water head pressure; $b$, experiment with water head pressure.

\subsection{Water Vapor absorption system}

A new set of experiment system for soft rock gas absorption (SRGA) was lately developped in GDUE. For the complex field conditions related to geotechnical projects, such as underground excavating, cultural relic preservation and etc., the SRGA system was developed to measure the water vapor sorption of soft rock samples. The system permits also the absorption of various gases, such as vapor, carbon dioxide (CO2), Nitrogen (N2) and even methane (CH4).

SRGA system can realize long time constant temperature, humidity and gas content control during the testing process as shown in Fig. 2. The SRGA testing system consists of the main body with two test chambers with gas supply station, control panel and a computer for automatic data acceptance and curve plotting. Test chamber 1\# is for gases mixing, the temperature, humidity and gas contents in the chamber reach set values before transferred to test chamber $2 \#$ where the samples with a maximum number of six are laid. The channels between two test chambers only open for a set period to make both test chambers reaching testing conditions, and after that the channels are closed and the test chamber $2 \#$ can perform the gas absorption test in a constant and undisturbed environment.

The value of environment temperature, humidity and different gases content can be set on the control panel before the test started, or change during the test processing if necessary. All the monitored environment parameters in test chamber are transferred to a computer, with the application of a software, the environment parameters and gases absorption of samples are collected and plotting automatically. Besides, all the data from the test is saved in a database file for further processing.

The technical parameters indexes are listed in Table 1 . The range of temperature is from -20 to $70^{\circ} \mathrm{C}$ which covers the natural climate variations, and the adjustable relative humidity range from 30 to $100 \%$. SRGA system can be set at a constant index to simulate specific environment parameters for the weathering mechanism research. The amplitude of parameters variation is 
Advances in Materials Science and Engineering: An International Journal (MSEJ), Vol. 3, No. 3, September 2016

controlled, for temperature is $\pm 1^{\circ} \mathrm{C}$, gas content $\pm 2 \%$, and relative humidity $\pm 4 \%$. To make the system more effective and reduce the period of reaching designed environment, the speed of temperature rise and down in test chamber 1\# is controlled, while the test chamber $2 \#$ operates smoothly for an undisturbed filed environment simulation.

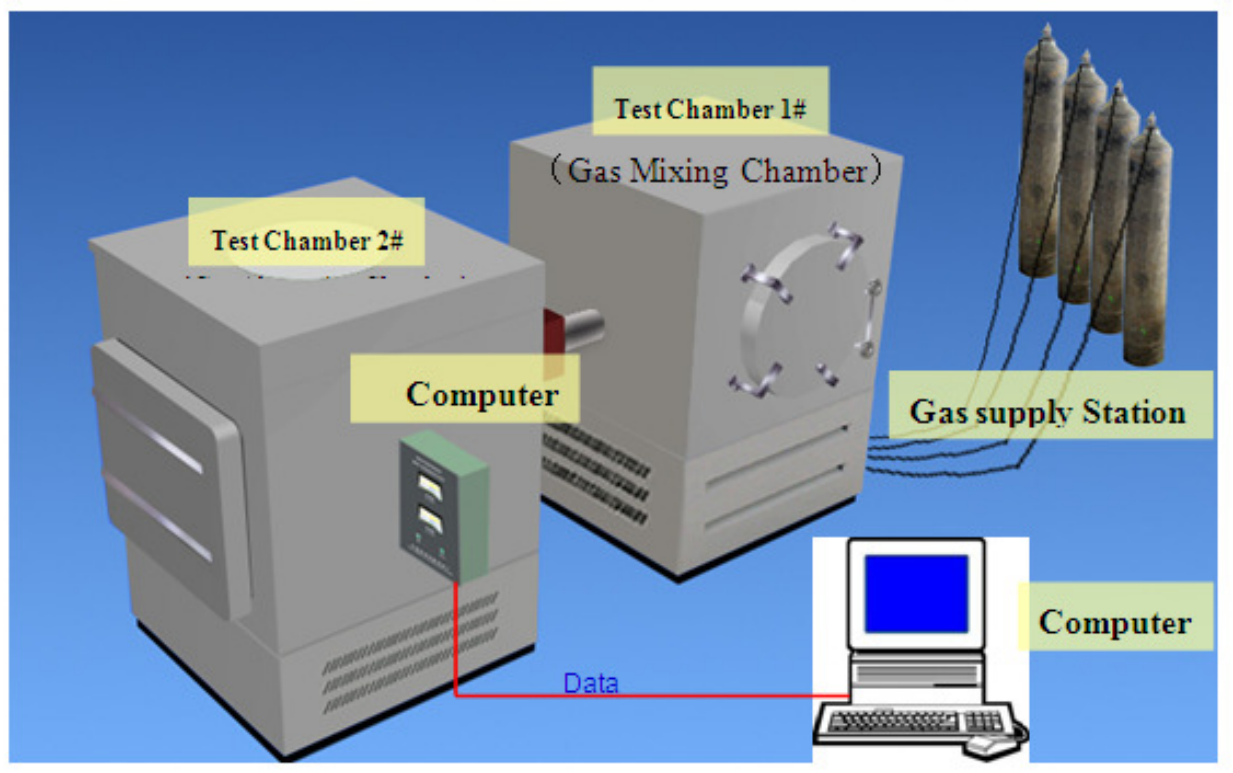

Fig.2 Composition of SRGA Experiment System

Table 1 Main Technical Parameters of SRGA System

\begin{tabular}{|c|l|c|}
\hline TYPE & \multicolumn{1}{|c|}{ Technical Parameters } & Range/Value \\
\hline \multirow{2}{*}{$\begin{array}{c}\text { Range } \\
\text { Index }\end{array}$} & (1) Adjustable Temperature Range & $-20 \beth \sim 70 \beth$; \\
\cline { 2 - 3 } & (2) Adjustable Relative Humidity Range & $30 \% \sim 100 \%$ R.H. \\
\hline \multirow{4}{*}{$\begin{array}{c}\text { Constant } \\
\text { Index }\end{array}$} & $\begin{array}{l}\text { (3) Temperature Constant Index } \\
\text { (Amplitude of variation in three days) }\end{array}$ & $=1 \square$ \\
\cline { 2 - 3 } & $\begin{array}{l}\text { (4) Gas Content Constant Index } \\
\text { (Amplitude of variation in three days) }\end{array}$ & $=2 \%$ \\
\cline { 2 - 4 } & $\begin{array}{l}\text { (5) Relative Humidity Constant Index } \\
\text { (Amplitude of variation in three days) }\end{array}$ & $=4 \%$ R.H. \\
\hline Temperature & $\begin{array}{l}\text { (6) Speed of temperature rise down } \\
\text { (In test chamber 1) }\end{array}$ & $10 \mathrm{Mm}$ \\
\hline
\end{tabular}




\section{CASE ON MOGAO GROTTOES SUPPORT ROCK}

\subsection{Background}

Mogao Caves are located at Gansu Province, Northwest China. From 4 A.D. century, the Caves started to be constructed along the east sedimentary strata precipice of Mingsha Mountain more than 1,600 meters from North to South. Previous study shows the damp environment and water effect are recognized as main factors threatening the pigment ground and plaster layers, support and surrounding rock [12-16]. Water is not only a direct and indirect cause of various damages, but also the vehicle for salt efflorescent in salination and weathering [17-20].

Field sense detection was widely used in the preservation environment of human heritages for water source analysis. Monitoring of major external environment parameters in Mogao caves were performed, such as temperature, humidity, and illumination [21-24]. In the field, two boreholes with seven detectors at different depth were drilled for rock mass characterization[25]. Acquired data of temperature and humidity were obtained for three years from 2008, and the seasonal rules of monitored parameters were summarized. The study found that temperature gradually decreases from shallow to deep, and temperature fluctuations trend to disappear after reach a certain depth around $2.5 \mathrm{~m}$ from the surface.

Samples for cultural relic preservation research can be divided into three kinds: natural, remolded and manmade samples. Natural samples are rare and remolded ones need natural material, while the manmade samples are based on the clear composition and ingredients of exact materials or simplification. Common indoor experiments and methods include the dry-wet cycle test, freezing and thawing cycle test, wind tunnel simulation test, water absorption test and water vapor absorption test etc. Despite numbers of studies have been carried out to study rock-water interaction, the experiments to seperate the mechanical effect of water absorption and the water vapor studies are limited. The interaction between water and cultural relics need more efforts in testing conditions control and data acquitting [26-32].

\subsection{Sampling}

Field sampling was performed with the support of Dunhuang Academy. Large numbers of samples are needed when carrying out experimental studies and are the best choice to ensure the accuracy, reliability and scientific of the results of the experiments. A set of undisturbed samples was employed. The sampling system, as shown in Fig. 3, includes a sampling rig, which can fix at any direction for sampling and the diameter of drilling tool is $5060 \mathrm{~mm}$ (Fig. 3a), a portable sample cutter (Fig. 3b) and portable sample box (Fig. 3c). After cutting has been completed, the standard sample is sealed with wax to ensure the undisturbed nature of samples.

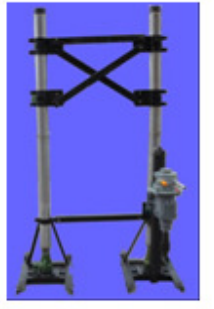

(a) field sampling rig

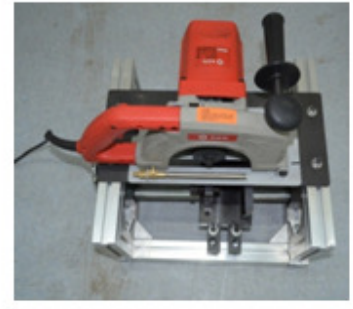

(b) portable samples cut sampler

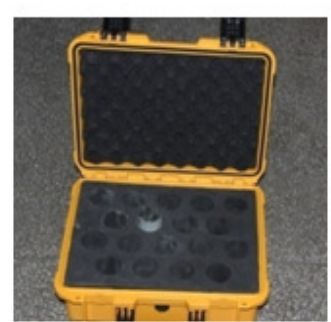

(c) portable sample box.

Fig.3 Undisturbed samples sampling system. 
Sampling was performed along the end of Mogao Caves precipice (Fig. 4a), and two types of rock, muddy sandstone and sandstone, were obtained as shown in Fig. 4b. Samples were processed to $\Phi 55 \times 110 \mathrm{~mm}$ cylindrical cores in the field, using rock drilling, portable cutting tools. To keep the in-situ condition of the samples, the cylindrical cores were cut and sealed before being transported to the laboratory.
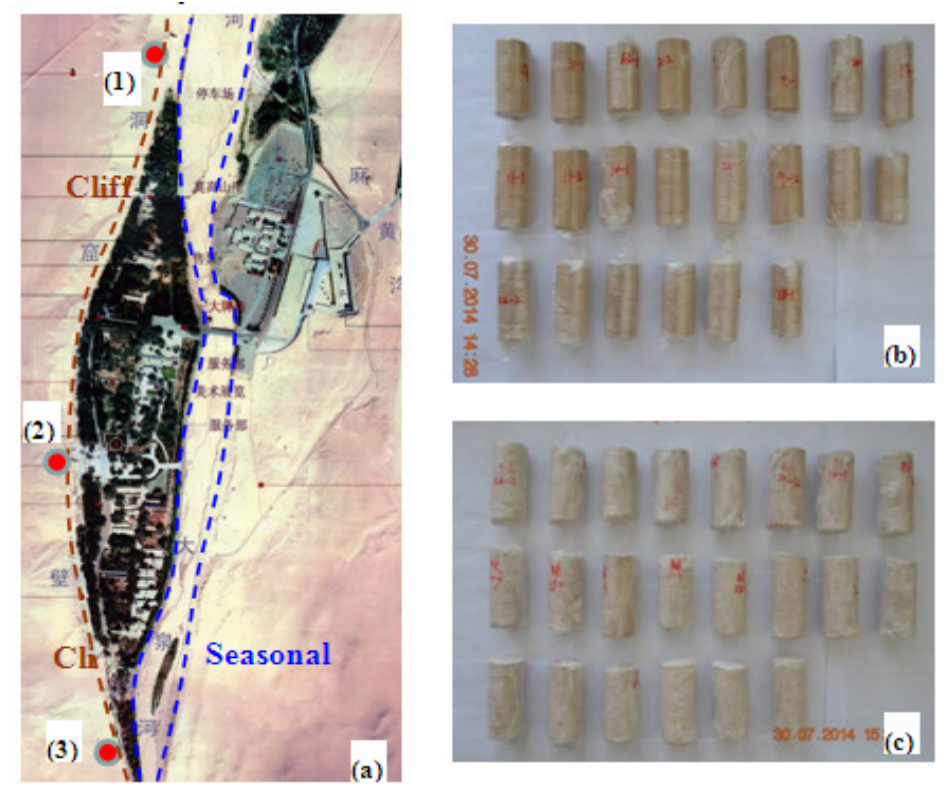

Fig.4 a, An Overview of Mogao Grottoes, (1) and (3) the sampling position,

(2) the Nine floors temple and Buddha; b, In-situ cut and sealed muddy sandstone samples; c, sealed sandstone samples.

\subsection{WA Tests}

Water absorption tests were performed on the muddy sandstone and sandstone samples separately. Firstly, the WA tests without water head pressure on muddy sandstone obtained the curves for the water absorption. As the mechanical test results showed, the UCS of this type of rock samples was lower than $1 \mathrm{MPa}$. During the WA tests, disaggregation were unavoidable, the water absorption processes were recorded before the disaggregation.

Figure 5 showed the curves of sample water content $\left(\mathrm{w}=\mathrm{m}_{\mathrm{WA}} / \mathrm{m}_{\text {sample }} * 100 \%\right)$ versus time, the critical WA value for muddy sandstone samples disaggregation was around $40 \%$.

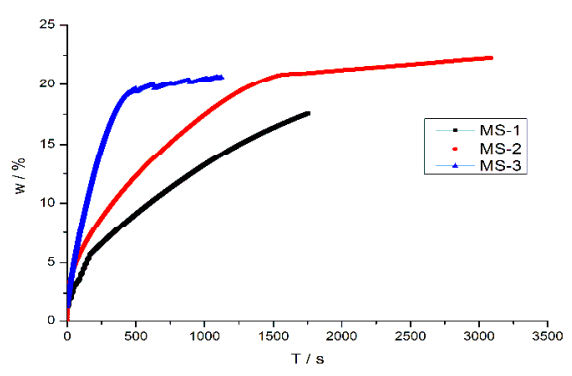

Figure 5. WA curves of muddy sandstone samples 
The photograph of MS samples after tests were shown in Figure 6. WA pressure tests were failed to perform on these samples because of the easy broken peculiarity.

WA tests were performed on the sandstone samples. The curves of WA tests with pressure was shown in Figure 7, and the water content (w) of sandstone was significantly lower than the muddy sandstone, but this type of rock still had large water absorb ability comparing to general hard rocks that performed in the laboratory before.

Figure 8 showed the WA tests without water head pressure and samples need more time to reach the equivalent value in the WA tests with pressure. The water absorption processes of soft rock would be the basis and support for the research on its engineering mechanical behaviors such as soften, weathering and salt movement and accumulation.

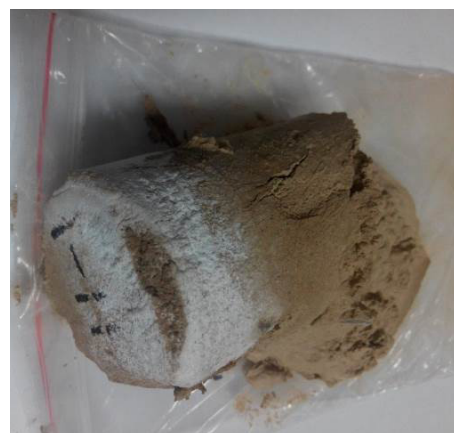

MS-1

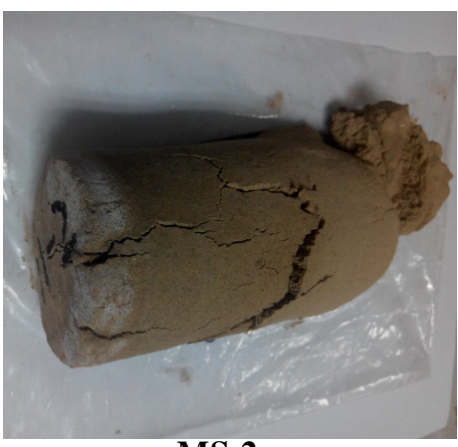

MS-2

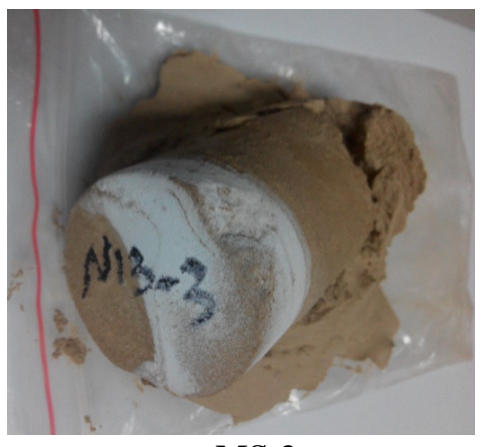

MS-3

Figure 6. Muddy sandstone samples after WA tests without water head pressure

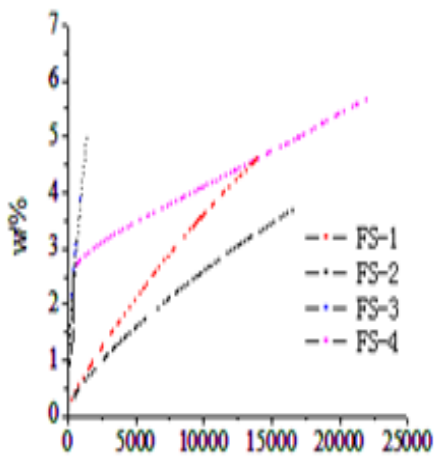

$t / s$

Figure 7 Curves of sandstone samples in WA test with pressure

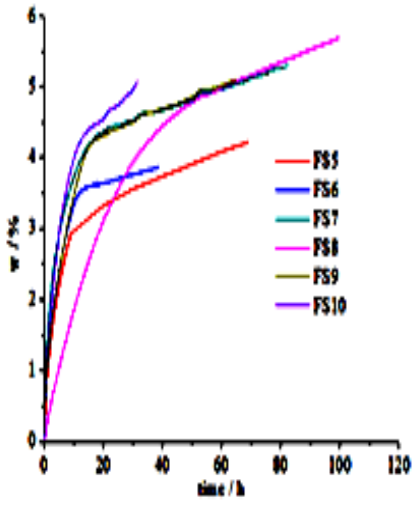

Figure 8 Curves of sandstone samples in WA test without pressure 
Advances in Materials Science and Engineering: An International Journal (MSEJ), Vol. 3, No. 3, September 2016

\subsection{SRGA Tests}

For the SRGA tests design, several of parameters combinations are employed and the PH value is set at 7 by using pure water at first stage, which is listed in Table 2 .

Table. 2 Samples and designed experimental parameters

\begin{tabular}{|c|c|c|c|c|c|}
\hline No. & Sample Code & Rock Type & Temperature Field & Humidity Field (\%) & Chemical Field \\
\hline 1.4 & $\begin{array}{c}6-2,8-2, \mathrm{~N} 9-2 \\
\mathrm{~N} 23-1\end{array}$ & Muddy Sandstone & 30 & 95 & \multirow{5}{*}{$\begin{array}{l}7 \\
\text { (Pure water is used to produce } \\
\text { water vapor and humidity } \\
\text { control) }\end{array}$} \\
\hline 5.8 & $\begin{array}{l}\text { N1-1, N3-1, } \\
\text { N17-1, N6-3 }\end{array}$ & Muddy Sandstone & 30 & 70 & \\
\hline $9-12$ & $\begin{array}{r}\text { N2-2, N5-1, } \\
\text { N10-1, N22-1 }\end{array}$ & Muddy Sandstone & 50 & 85 & \\
\hline $13-14$ & 11-1, 21-1, & Muddy Sandstone & \multirow[t]{2}{*}{20} & \multirow[t]{2}{*}{95} & \\
\hline $14-16$ & S14. S17.1 & Sandstone & & & \\
\hline
\end{tabular}

The vapor absorption curves are obtained in each group of tests, as showing in Figure 5. Fig. 5a shows the first coupled environment by setting the temperature at $30^{\circ} \mathrm{C}$ and relative humidity 95\%. The constant environment in test chamber 2\# was reached after 20 hours from the test start. The unstable changing of environment humidity for the first stage brings obvious influence on the absorption rate. Curves became smooth in the constant stage of the test.

To avoid the effect produced by the adjustment stage of environment parameters, the control of system was optimized and we delayed the occasion to place test samples in test chamber 2\#. Fig. $5 \mathrm{~b}$ shows a designed environment with lower relative humidity. The impulse of humidity was later found caused by the humidifier. Figs. $5 \mathrm{c}$ and $5 \mathrm{~d}$ show the other two of the tests, and the absorption ability of muddy sandstone is much larger than that of sandstone.
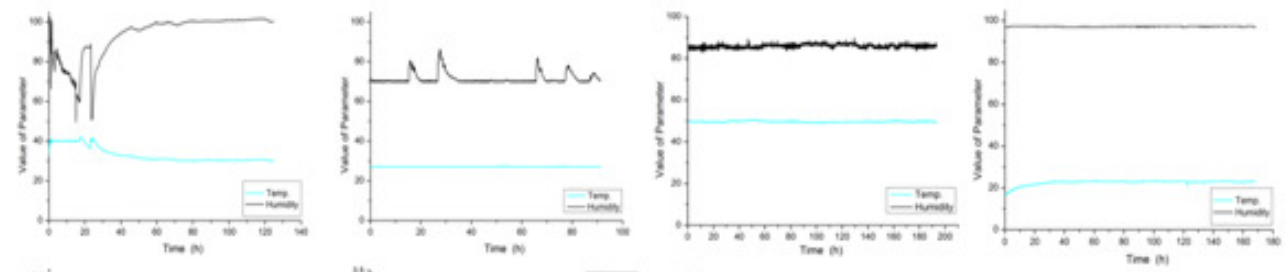

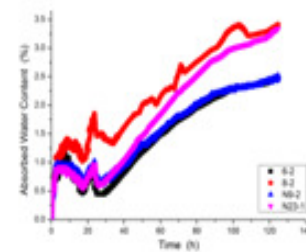

(a)

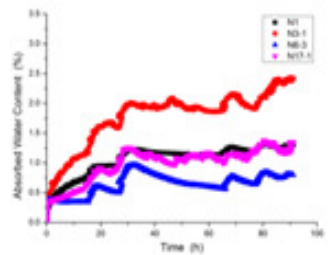

(b)

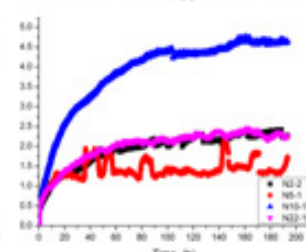

(c)

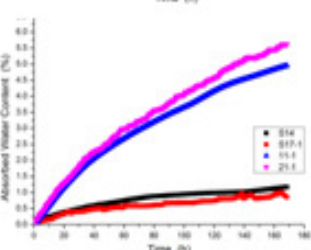

(d)

Figure 9. Monitored Environment Parameters and Absorption Curves 
Some of typical photographs of samples before and after experiment are displayed in Figure 10. The muddy sandstone has a larger vapor absorption rate and loose weight rapidly, forming surface damages. And the strength is reduced sharply; the sample N10-1 in Figure 6a was cracking when we try to move it out from test chamber 2\#, which is the same as the macroscopical flaking, exfoliation and many other damages on Mogao Caves. The sandstones showing in Fig. 10b had little changes from observation.
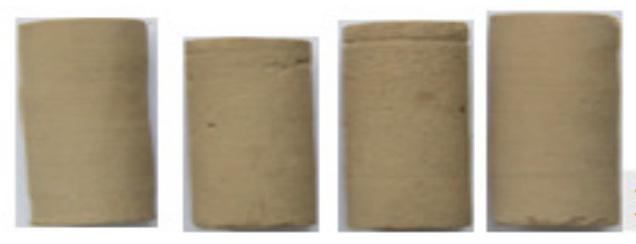

Before Test

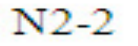

N5-1 N10-1 N22-1

$(\mathrm{a}-1)$
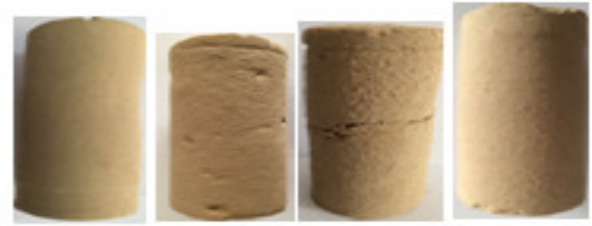

\section{After Test \\ $(\mathrm{a}-2)$}

N2-2 N5-1 N10-1 N22-1
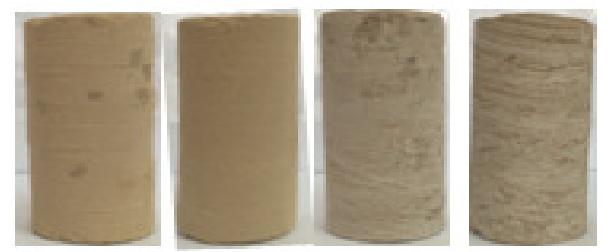

Before Test

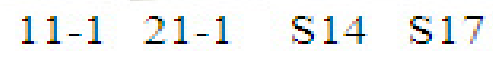

(b-1)
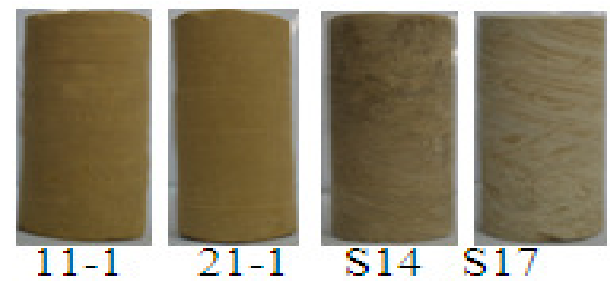

\section{After Test}

$(\mathrm{b}-2)$

Figure 10. Typical Samples Before and After Tests

\subsection{Additional tests}

\section{(1) X-ray diffraction}

X-ray diffraction experiments were employed in the mineral analysis of Mogao Caves rocks. The mineral composite of muddy sandstone and sandstone is listed in Table 3. The content of quartz and feldspar in both type of rock is similar, but the muddy sandstone is rich in calcite from sedimentation. The content of clay mineral in both types is high, with 17.2 and $29.7 \%$. For a 
further study, the relative content of clay minerals is considered, and two types of rock show fairly good consistency.

Table 3 Mineral Type and Content of Dunhuang Mogao Samples

\begin{tabular}{|c|c|c|c|c|c|c|c|c|c|c|c|}
\hline \multirow[b]{2}{*}{ Rock Type } & \multicolumn{7}{|c|}{ All Minerals Content (\%) } & \multicolumn{4}{|c|}{ Clay Mineral (\%) } \\
\hline & Quartz & $\begin{array}{c}\text { Potash } \\
\text { Feldspar }\end{array}$ & $\begin{array}{l}\text { Soda } \\
\text { Feldspar }\end{array}$ & Calcite & Dolomite & Homblende & Clay Minerals & S & I & $\mathrm{K}$ & $\mathrm{C}$ \\
\hline Muddy Sandstone & 24.1 & 0.6 & 8.9 & 43.9 & 3.7 & 1.6 & 17.2 & 0 & 68 & 8 & 24 \\
\hline Sandstone & 24.3 & 0.5 & 6.3 & 22.8 & 16.4 & 1 & 29.7 & 0 & 66 & 10 & 24 \\
\hline
\end{tabular}

(S, smectite; I, illite; K, kaolinite; C, chlorite.)

\section{(2) SEM Test}

SEM experiments were used for the microstructure analysis of Mogao samples. According to the SEM experiment results analysis of selected samples, the clay minerals are in the form of conglomerate in both muddy-sandstone and sandstone in Mogao Caves (see Figure 11and 12), but the difference laying in the microstructure between muddy-sandstone and sandstone is obvious that the former has a larger surface porosity factor. Besides, the connection of large and small pore or micro cracks leads to joint development, which makes water or vapor even faster transmission, and further softening, disintegration and swell, and finally sharply reduce the strength of rock [32-34].

The vapor absorption of Dunhuang Mogao support is mainly influenced by the environment temperature, humidity, microstructure and clay minerals. Based on the laboratory tests and additional tests test results, the clay mineral content in sandstone is about $30 \%$ and larger than muddy sandstone, but the vapor absorption ability is lower. The primary effect factor of vapor absorption between different types of support rock in Mogao Caves is the microstructure [35-37]. The SEM experiment results show that the clay mineral expand after water absorption in both muddy sandstone and sandstone samples. Both the material is unconsolidated and porous from the view of photographs magnified 1,200 times, but the compactness of sandstone is comparable larger with few pores or discontinuity when magnified 5,000 times.
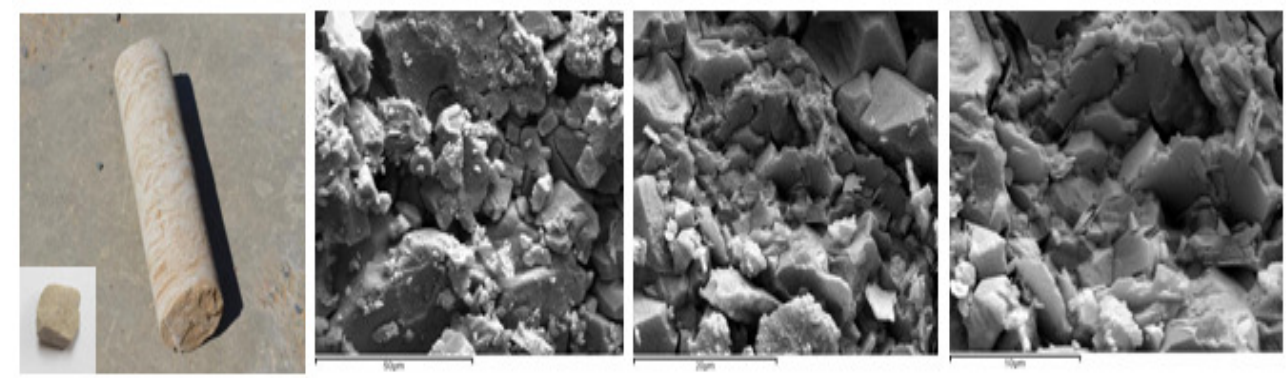

Figure 11. SEM Results of sandstones 
Advances in Materials Science and Engineering: An International Journal (MSEJ), Vol. 3, No. 3, September 2016
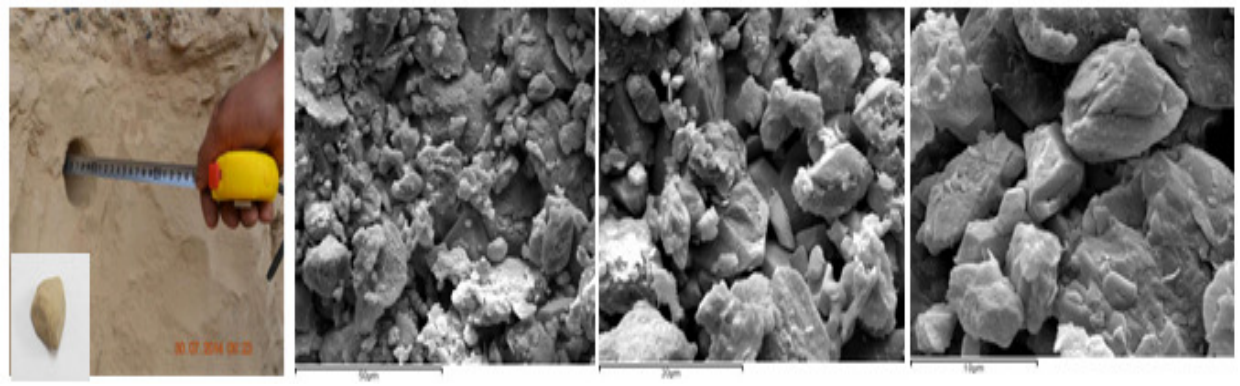

\section{(3) Rock Soften}

Figure 12. SEM Results of Muddy Sandstones

Water absorption can cause soft rock softening, and the strength of soft rock is reducing with the increase of water content $[33,34]$. Mechanical tests were performed on sandstone samples with different water content by WA tests. When taken out from the chamber of WA system, the rock samples were immediately set on the UCS test system, as showing in Figure 13.
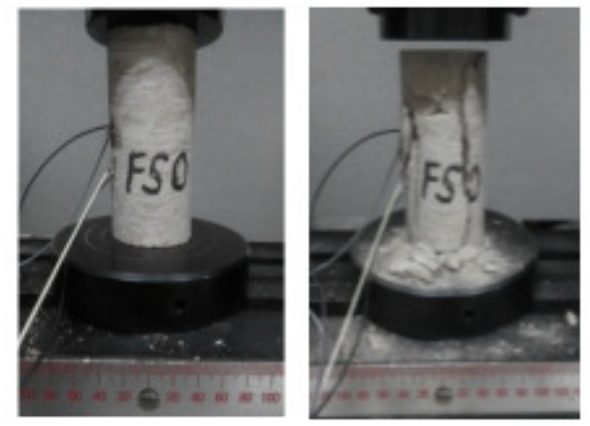

Figure 13. UCS Tests on Rock Samples with different water content

The stress-strain curves were shown in Figure 14. The FS0 was put into the drying system for 24 hours, and the mass of sample changed little from the natural sample because the weather in Dunhuang, located in the northwesten China, was normally dry

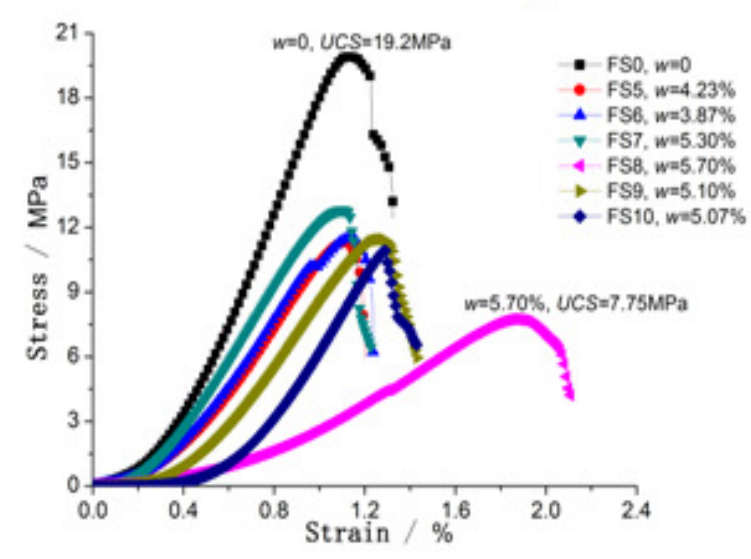

Figure 14. Stress-strain curves on sandstone samples with different water content 
The natural strength of the sandstone was obtained as about 19.2 MPa. Samples FS5 to FS10 were in the WA tests as introduced in the last section and then in the UCS tests. Results showed that the UCS decresed rapidly when the water content increased. When the sandstone exposed to water for 100 hours, see curve of FS 8 in the figures, the strength reduced to $40 \%$ of the natural one, which could cause serious damage and geological disasters in the field.

\section{CONCLUSIONS}

Soft rocks always present undesirable behaviors and cause many engineering problems and one of the significant effect factors is the water. For the study on the interaction between water and soft rocks, two series of laboratory experiment systems were developed in the GDUE, China. Testing of the systems and experiment methords were introduced discussed through an engineering project on Dunhuang Mogao support rock weathering effected by water.

Decades of work in the protection and preservation of cultural relics, represented by Mogao Caves, provided solid foundations on theory and mechanisms related to the knowledge of the rock mass environment. However, the knowledge of Mogao Cvaes surrounding rocks, the muddy sandstone and sandstone, and water interactions remains insufficient, particularly in water vapor effect.

Field sampling was performed in Dunhuang Mogao, and the same type of rock samples as Mogao Grottoes support rock are obtained. The WA tests and SRGA tests for water vapor absorption were performed on these samples by the developed experiment systems. The absorption processes could be recorded and the disaggregation, salt transprotion, surface weathering and softening process of soft rocks were reproduced in the laboratory.

For the further understanding the interaction and mechanisms, additional tests were employed for a better knowledge of basic information of mineral content and microstructure of different types of rock. The presented results show that the the clay mineral content in sandstone is about $30 \%$ and larger than muddy sandstone, and the microstructure is one of the primary effect factors for Dunhuang support rocks.

For muddy sandstone, water can easily cause the material disaggregation, and the factors of temperature and relative humidity are involved, and dynamic change of vapor sorption of conglomerate rock generally followed an exponential law. For sandstone, the UCS decresed rapidly with the increased of sample water content. Long time exposion to water can cause the strength reduced to $40 \%$ of the natural rock, which could be serious risks in the field preservation of cultural relics.

Besides, the studies related to water sorption influencing parameters and vapor-induced strength weakening and microstructure changes are critical for improved understanding of rock preservation in Mogao Caves. But there are still more laboratory tests with chemical and mechanical analysis, numerical simulations on microstructure studies should be performed for a better guidance for cultural relics protection and preservation. 
Advances in Materials Science and Engineering: An International Journal (MSEJ), Vol. 3, No. 3, September 2016

\section{ACKNOWLEDGEMENTS}

Financial supports of this study was provided by the National Natural Science Foundation of China (51134005), and by the Major Projects of Science and Technology in Gansu province, China (1102FKDF014).

\section{REFERENCES (Please Follow The Guidelines)}

(1) Milton Assis Kanji. Critical issues in soft rocks. 2014. Journal of Rock Mechanics and Geotechnical Engineering, 6(2014) 186-195.

(2) Fan Jinshi. 2014. Guarding Dunhuang art treasures, inherit human heritages -The seventieth anniversary of Dunhuang academy. Dunhuang Research: 1-5. (In Chinese)

(3) Yoshinori Iwasaki. Earthquake environment and micro-tremor characteristics of Mogao Grottoes. International Symposium on Conservation of Ancient Sites on the Silk Road 2014, 32-35.

(4) Shi Yucheng, Xu Huiping, Wang Xudong. Seismic safety evaluation of Dunhuang Mogao Grottoes. Dunhuang Research, 2000, 01: 49-55. (In Chinese)

(5) Baldin A, Gorassini A, Priinci E, et al. 2009. Effects of Artificial Weathering on the Mechanical Properties of Paper-Based Materials Consolidated with Polymeric Materials. Journal of AppliedPolymer Science, 112: 3529-3536.

(6) Zhang Zhengmo, Liu Hongli, Guo Qinglin, Wang Xudong, Xue Ping. Sudden rain risks to the Mogao Grottoes cave micro environmental impact analysis. Dunhuang Research, 2013,01: 120-124. (In Chinese)

(7) He Manchao, et al. Engineering Mechanics of Soft Rock [M], Beijing: Science Press, 2002. (In Chinese)

(8) He Manchao, Yang Xiaojie, Sun Xiaoming. Soft rock characteristics study of the clay minerals in China's coal mine $[\mathrm{M}]$. China Coal industry publishing house, 2006. (In Chinese)

(9) M.C. He. 2014. Latest progress of soft rock mechanics and engineering in China [J]. Journal of Rock Mechanics and Geotechnical Engineering, 20146 (3): 165-179.

(10) M.C. He, Z.J. Fang, P. Zhang. Theoretical studies on the defects of kaolinite in clays[J]. China Phys Lett, 26 (2009), pp. 059101-059104

(11) M.C. He, J. Zhao, Z.J. Fang, P. Zhang. First-principles study of isomorphic ('dual-defect') substitution in kaolinite[J]. Clays Clay Miner, 59 (5) (2012), pp. 501-506.

(12) Huang Jizhong, Yuan Daoxian. Water-rock interaction research and Yungang Grottoes stone carving weathering diseases research [A], Proceedings of 2005 Yungang international academic symposium on Yungang grottoes research, Yungang grottoes research institute, 2005:9. (In Chinese)

(13) Daisuke OGURA, Ping XUE. Deteriorating mechanism caused by environment of mural paintings in Mogao Cave 285, Dunhuang. International Symposium on Conservation of Ancient Sites on the Silk Road 2014, 24-25.

(14) Abu Bakr Moussa, Nikolaos Kantiranis, Kontantinos S. Voudouris, et al. Diagnosis of weathered Coptic wall paintings in the Wadi El 1Natrun region, Egypt [J]. Journal of Cultural Heritage, 2009, 10: 152-157.

(15) A. Kriznar, V. Munoz, M. A. Respaldiza, et al. Portable XRF study of pigments applied in Juan Hispalense's 15th century panel painting[J]. X - Ray Spectrom. 2011, 40, 96-100

(16) Chen Gangquan, Yu Zongren. Murals herpes and ground layer soluble salt alysis of in Mogao Cave 351. (In Chinese)

(17) WANG X D,ZHANG H Y,ZHANG M Q. Stabilization and consolidation of Mogao Grottoes in China. Preservation of Natural Stone and Rock Weathering. 2007

(18) E. Ruiz-Agudo, B. Lubelli, A. Sawdy, R. van Hees, C. Price, C. Rodriguez-Navarro. An integrated methodology for salt damage assessment and remediation: the case of San Jeronimo Monastery 
Advances in Materials Science and Engineering: An International Journal (MSEJ), Vol. 3, No. 3, September 2016

(Granada, Spain). Environmental Earth Sciences, 2011, 63: 1475-1486

(19) Eva Kotulanová, Jana Schweigstillová, Petr Bezdi ka, et al. WALL PAINTING DAMAGE BY SALTS: CAUSES AND MECHANISMS [J]. Acta Research Reports, 2009, 18, 27-31

(20) Eva Kotulanová, David Hradil, Janka Hradilová, et al. Degradation of lead-based pigments by salt solutions [J]. Journal of Cultural Heritage, 2009, 10(3):367-378

(21) Huang.Ji-zhong. Mechanism of water condensate formation on the sandstone surface in Yungang grottoes. Proceedings of Conference on Masonry Cultural Relics Protection, China cultural heritage protection technology association.2004:25. (In Chinese)

(22) Cao Wenbing, Wan Li, Zeng Yijian, et al. Yungang grottoes water condensate formation mechanism research and prevention. Proceedings of 2005 Yungang international academic symposium on Yungang grottoes research, Yungang grottoes research institute, 2005:8. (In Chinese)

(23) Maekawa, Liu Gang, Xue Ping, 2000. micro climate environment monitoring and research in Mogao Cave 85. Dunhuang Research, 2000: 36-41. (In Chinese)

(24) Lin Bo, Wang Xudong, Guo Qinglin, et al. Research on change laws of cave wall rock mass temperature and humidity in Mogao Cave 1-8. Dunhuang Research, 2013, 01: 86-91. (In Chinese)

(25) Yang Shanlong, Wang Xudong, Guo Qinglin, et al. Preliminary analysis of moisture distribution in Dunhuang Mogao Grottoes cliff body. Hydrogeology and Engineering Geology, 2009, 05: 94-97. (In Chinese)

(26) Mooney, R.W., Keenan, A.G., Wood, L.A., 1952a. Adsorption of water vapor by montmorillonite. II. Effect of exchangeable ions and lattice swelling as measured by X-ray diffraction. Journal of the American Chemical Society 74 (6), 1371-1374.

(27) Mooney, R.W., Keenan, A.G., Wood, L.A., 1952b. Adsorption of water vapor by montmorillonite. I. Heat of desorption and application of BET theory 1. Journal of the American Chemical Society 74 (6), $1367-1371$.

(28) Shang, S., Horne, R.N., Ramey, H.J., 1994. Water vapor adsorption on geothermal reservoir rocks. Geothermics 24 (4), 523-540.

(29) Pennell, K.D., Rhue, R.D., Rao, P.S.C., Johnston, C.T., 1992. Vapor-phase sorption of p-xylene and water on soils and clay minerals. Environmental Science \& Technology 26 (4), 756-763.

(30) Gruszkiewicz, M.S., Horita, J., Simonson, J.M., Mesmer, R.E., Hulen, J.B., 2001. Water adsorption at high temperature on core samples from the geysers geothermal field, California, USA. Geothermics 30 (2-3), 269-302.

(31) Miniotaite, R., 2004. Water vapour permeability and sorption of painted substrates. 8thInternational Conference on Modern Building Materials, Structures and Techniques, pp. 109-113.

(32) N. Zhang, M.C. He, P.Y. Liu. Water vapor sorption and its mechanical effect on clay-bearing conglomerate selected from China. Engineering Geology, 141-142 (2012) 1-8.

(33) Likos, W.J., Lu, N., 2002. Water vapor sorption behavior of smectite-kaolinite mixtures. Clays and Clay Minerals 50 (5), 553-561

(34) Erguler, Z.A., Ulusay, R., 2009. Water-induced variations in mechanical properties of clay-bearing rocks. International Journal of Rock Mechanics and Mining Sciences 46 (2), 355-370.

(35) Yilmaz, I., 2010. Influence of water content on the strength and deformability of gypsum. International Journal of Rock Mechanics and Mining Sciences 47 (2), 342-347.

(36) Feng, X.T., Chen, S., Li, S., 2001. Effects of water chemistry on microcracking and compressive strength of granite. International Journal of Rock Mechanics and Mining Sciences 38 (4), 557-568.

(37) Feng, X.T., Li, S.J., Chen, S.L., 2004b. Effect of water chemical corrosion on strength and cracking characteristics of rocks-a review. Key Engineering Materials 261-263, 1355-1360. 